\title{
Ionic Liquids within Microfluidic Devices
}

\author{
Marina Cvjetko ${ }^{1}$ and Polona Žnidaršič-Plazl ${ }^{2}$ \\ ${ }^{1}$ Faculty of Food Technology and Biotechnology, University of Zagreb, \\ ${ }^{2}$ Faculty of Chemistry and Chemical Technology, University of Ljubljana, \\ ${ }^{1}$ Croatia \\ 2Slovenia
}

\section{Introduction}

In past decade, the use of ionic liquids as the replacement for conventional molecular solvents in organic reactions has tremendously increased, both in academia as well as in industry. Features that make ionic liquids attractive for use in organic synthesis in general and catalytic processes in particular include their insignificant vapor pressure (even at elevated temperatures), great dissolving power for a wide range of otherwise sparingly soluble compounds, non-flammability, and thermal, chemical and electrochemical stability. Another important feature of these liquids is the possibility of tuning their physical and chemical properties by varying the nature of an anion and/or a cation in order to improve their miscibility with water or organic solvents, to increase extraction capacity or to enhance enzyme stability/activity when used as media for biocatalytic reactions. The number of possible chemical structures is extremely high, and it enables to tailor the best ionic liquid for a specific application (Park \& Kazlauskas, 2003; Yang \& Pan, 2005).

Recently, ionic liquids were found to be much more than just green solvents. They might be used also as additives in new materials, as well as in a variety of (bio)chemical catalytic reactions, where they could act as supports for catalyst immobilization or even as catalysts (Gorman, 2001).

The production of ionic liquids in high purity, which is essential for their application, is a special challenge due to the extreme heat release during the alkylation step leading to low product quality. Insufficient mixing in conventional batch synthesis procedures represents a major problem for large-scale production. Besides, additional purification processes required to obtain ionic liquids with satisfying purity significantly increase overall production costs, leading to limited potential for industrial application. Therefore there is a great demand for the development of alternative processes of ionic liquids synthesis as well as for their application.

Implementation of microstructured devices offers a promising solution to this type of challenge due to several advantages leading to process intensification, which was already impressively demonstrated in many chemical and biochemical processes (Hessel et al., 2004a; Pohar \& Plazl, 2009). Microfluidic systems are also an extremely efficient tool for the rapid screening of (bio)catalysts and for biocatalytic process design and analysis as well. In recent years, a successful application of enzymatic microreactors has been reported, mainly in chemical analysis and kinetic studies (Urban et al., 2006). Their use as components of 
integrated systems, often termed lab-on-a-chip, or in micro total analysis ( $\mu$ TAS) for analysis of biomolecules, is growing every year. However, the implementation of enzymatic microreactors into industrial-scale synthesis is relatively scarce (Žnidaršič-Plazl \& Plazl, 2009). Furthermore, the potential for the use of ionic liquids in enzymatic reactions as well as for product isolation within microstructured devices is not yet exploited.

The present work aims to provide a literature review of the implementation of microreactor technology into the synthesis of ionic liquids, into (bio)catalyzed production of commercially important chemical compounds with ionic liquids as sustainable solvents, as well as in downstream processing with ionic liquids.

\section{Advantages of microfluidic devices}

Microreactor technology has uncovered new scientific solutions and challenges in a broad range of areas, from the electronic industry, chemical industry, medical technology, biotechnology, to fuel production and processing, environmental protection, and process safety (Ehrfeld et al., 2000). It is based on continuous flow chemistry through microchannels with a typical height or width of less than $1 \mathrm{~mm}$. Besides continuous way of operation, the use of parallel microreactor modules provides access to kilogram or even ton quantities, thus making the technology also suitable for large-scale, commercial production (Pavlou, 2009). The concept of numbering-up avoids bottlenecks usually present at scaling up and yet very short time is needed for transferring a process in a microreactor from research on the lab scale to pilot and production scale.

Due to significantly higher surface-to-volume ratios and superior heat exchange properties compared to conventional reactions system, these micro- or submillimeter devices are extremely efficient tools for existing (bio)chemical synthesis and downstream processing. The implementation of microstructured devices into these processes offers great reaction selectivity, improved kinetics and overall yields, minimal reagent and solvent volumes, easy process control and automation to improve operator safety and reduce human errors, and improved sustainability with reduced waste at low energy consumption. The small hold-up and the large specific transport rates result in extremely short response times, providing a favorable basis for efficient process control (Jähnisch et al., 2004; Hessel et al, 2004a). Due to increased process intensification and possibility of numbering up offered by microreactor technology, more traditional pilot-scale reactor systems and pilot plant systems may be replaced, at least in some cases, by smaller, faster responding, more flexible mini-plants with reduced capital and operating costs (Mills et al., 2007; Pohar \& Plazl, 2009).

\section{Synthesis of ionic liquids within microreactors}

High purity of ionic liquids and overall production costs are crucial factor for their application in the industry. Therefore, a lot of effort was put into overcoming the difficulties regarding the preparation of ionic liquids. In order to understand the need for alternative synthesis of ionic liquids, the problems of conventional batch synthesis will be briefly discussed.

\subsection{Problems associated with the preparation of ionic liquid}

Ionic liquids could be prepared in one-step reaction, although usually two consecutive steps are employed: the formation of the salt with the desired cation, followed by the reaction for 
anion exchange (metathesis). The majority of the ionic liquids are prepared via alkylation of a nitrogen containing heterocycle, such as 1-substituted imidazole, followed by salt metathesis (Figure 1). Alkyl halides (chloroalkanes, bromoalkanes, and iodoalkanes) are widely used as alkylating agents in a quaternization reaction, since they are cheap and easily available. Metathesis step is usually achieved by addition of the alkali salt of the desired anion (with precipitation of the alkali halide salt).

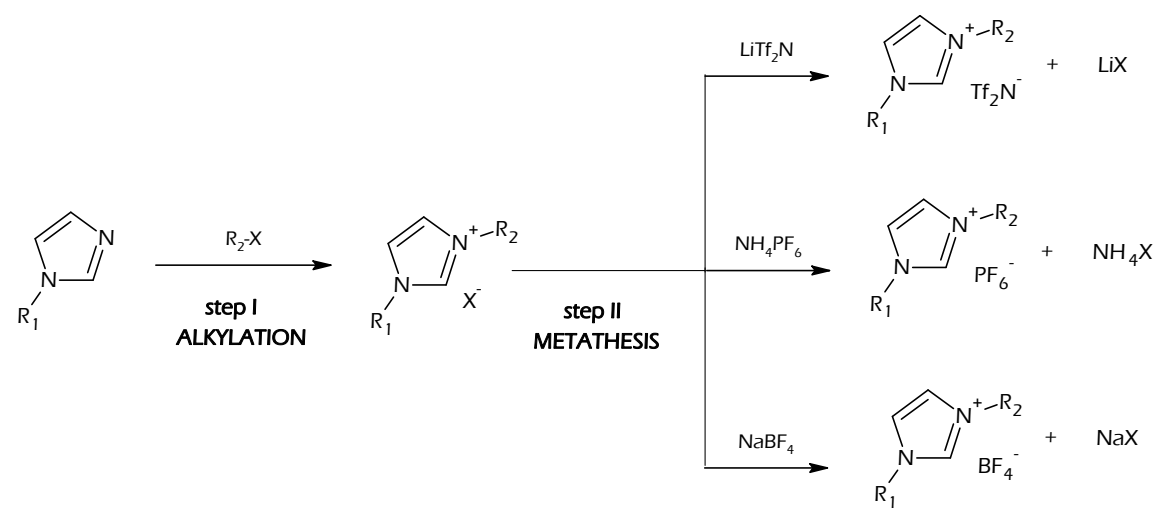

Fig. 1. Standard route to 1-alkyl-3-methylimidazolium-based ionic liquids.

At first sight, batch alkylation is a simple reaction: the amine and the desired alkyl halide are mixed and the reaction mixture is heated, typically in an inert atmosphere $\left(\mathrm{N}_{2}\right.$ or Ar). In batch alkylation many difficulties arise due to long reaction times (up to $72 \mathrm{~h}$ ) at relatively high temperature, depending on the reactivity of the alkyl halide. Conventional batchsynthesis procedures fail to yield products with purities higher than about $96 \%$. Due to incomplete conversion in standard batch procedure, intensive purification steps are needed (Gonzales et al., 2009). Purification cannot be achieved by simple distillation methods used for conventional organic solvents due to high boiling points of these compounds $\left(>300^{\circ} \mathrm{C}\right)$, but rather it requires the use of harmful organic solvents such as acetonitrile, ethyl acetate or tetrahydrofuran, which is contrary to green chemistry principles. Non-conventional techniques such as irradiation with microwaves (Loupy, 2006) and power ultrasound (Cravotto \& Cintas, 2006), have been intensively studied and have considerably improved ionic liquid synthesis by cutting down reaction times and improving yields.

Ideally, ionic liquids should be colorless (at least in the absence of functional groups), clear, odorless and free flowing liquids (Dyson \& Geldbach, 2005). The formation of »hot spots", caused by poor mixing, can have detrimental effect on the quality of the obtained ionic liquid, manifested by the product colorization (Bowing \& Jess, 2005). Löb et al. (2007) demonstrated that even a dropwise addition of alkylating agent to the bulky amine in a labscale batch vessel gave raise of a local temperature of the mixture up to $150{ }^{\circ} \mathrm{C}$. The chemical entities of the coloring matter are still not clear, but several authors agree that imidazolium species participate in the creation of colored compound, either by its polymerization or decomposing at high temperature (Renken et al., 2007). Therefore, in order to improve the purity of ionic liquids, an efficient removal of released reaction heat is crucial. To avoid reaction mixture overheating, solvents such as 1,1,1-trichloroethane, ethyl acetate, acetonitrile or toluene are usually used in the reaction. On the other hand, application of 
solvents leads to very long processing time and introduces unwanted environmentally harmful compounds (Waterkamp et al., 2009; Hu et al., 2010).

The use of microreactors in ionic liquid synthesis is therefore a very promising alternative, mainly due to the very effective mixing and temperature control, corresponding to reaction control, leading to high-quality, (near)colorless products at shorter reaction times (without the necessity of subsequent purification steps), and higher space-time-yields (Hessel et al., 2005; Waterkamp et al., 2009).

\subsection{Design of the microstructured reactors for ionic liquids synthesis}

Microfluidic devices allow for processing small volumes $\left(10^{-9}\right.$ to $\left.10^{-12} \mathrm{~m}^{3}\right)$ of fluid within channels and are compatible with continuous flow mode of operation (Fernandes, 2010). Hence, the use of microscale devices in preparation of ionic liquids is potentially as 'green' as chemical synthesis can be; as reagents are quantitatively converted into the final product, no solvents are needed for synthesis or purification and absolutely no waste is generated (Ehrfeld et al, 2000). Wilms et al. (2009) reported that less than $1 \%$ of impurities, mostly unreacted starting material, are present in ionic liquids synthesized within microfluidic devices. Hu et al. (2010) showed that microchannel reaction system is also suitable for the kinetic study of fast reactions with high heat release and/or a viscous system, such as alkylation of imidazolium species.

In Figure 2, a general scheme for a continuous ionic liquid production in a microreactor is presented. The core part of the microscale production set-up is a micromixer in which amine and alkylating agent are rapidly mixed, linked to the reaction tube.

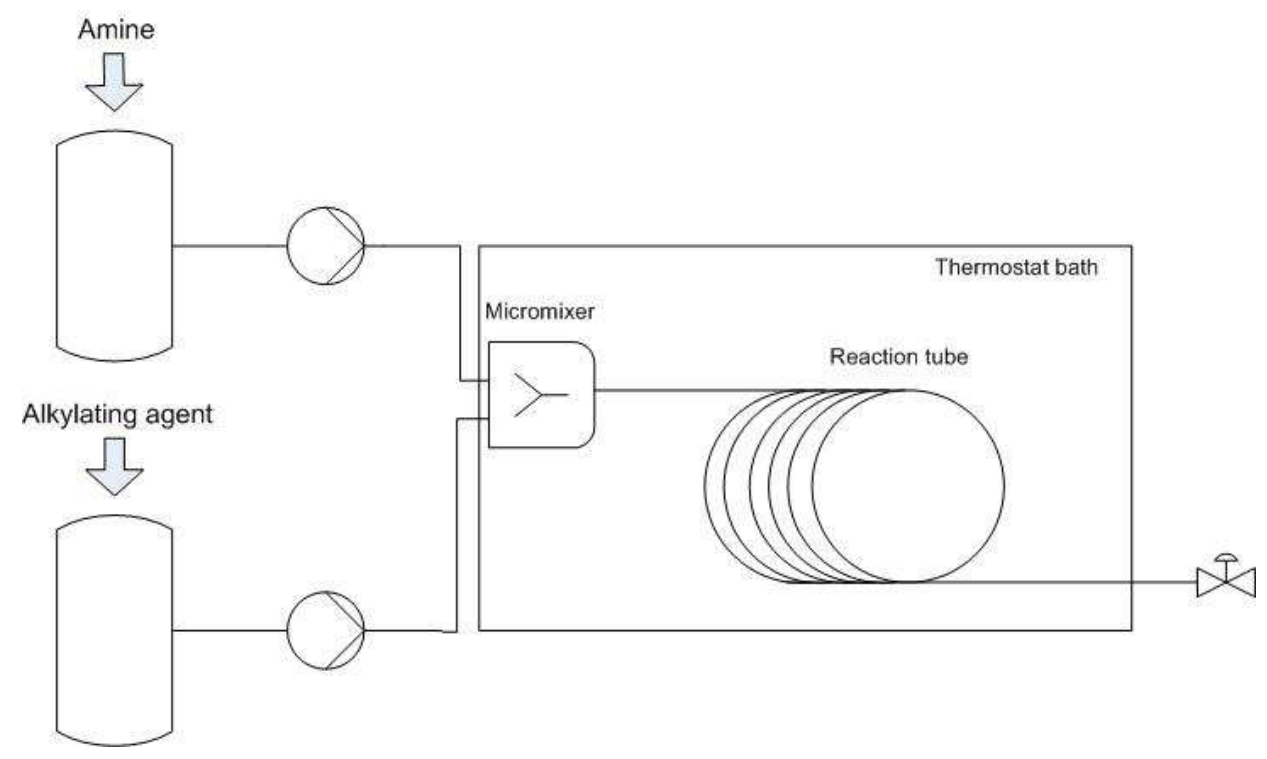

Fig. 2. General scheme of an experimental set-up for ionic liquid synthesis comprising of a micromixer and a (micro)tubular reactor.

The reactants are pump driven into capillaries that are usually heated to reaction temperature, mixed in the micromixer and then directly guided into temperature regulated 
section of the reaction section. Since residence times in the micromixers are in the range of milliseconds, very small conversions are achieved, and therefore no significant temperature increase is observed in this section (Löb et al., 2007). The reaction mainly takes place in the following tubular reactor with diameters of less than $1 \mathrm{~mm}$, or in a millimeter or even in a centimeter scale (Hessel et al., 2004b). The necessary residence time for the reaction can be adjusted by changing the flow rate and/or the length of the reaction tube. The capacity of the reactor system can be increased by simply numbering up of the system, allowing to achieve even multikilograms of ionic liquids per day (Wilms et al., 2009).

Due to the fact that the physical dimensions of the flow structures in microfluidic systems are in the micro-scale, the Reynolds numbers characterizing fluid-flow in microfluidic systems are well below the critical value for turbulence and the flow regime is, consequently, laminar (Pohar \& Plazl, 2008). Therefore, micromixers in microfluidic systems rely on molecular diffusion. In general, micromixers used for ionic liquid synthesis are designed in such a way that their internal flow geometries reduce diffusion distances. Some examples of micromixers used for ionic liquid synthesis are shown in Figure 3.


Fig. 3. Different micromixer designs: a) Vortex-type micromixer (Adapted from Waterkamp et al. (2007). Reproduced by permission of the Royal Society of Chemistry; b) Slanted groove micromixer (Sabotin et al., 2010); c) SIMM-V2 micromixer (Adapted from Hu et al., 2010). Reproduced by permission of Elsevier)

Due to the problems regarding overheating and temperature control during ionic liquid synthesis, a lot of effort was put into designing of an efficient system for temperature control. The simplest temperature control could be achieved by embedding the whole reactor system in thermostat bath (Ranken et al., 2007; Löb et al., 2007; Wilms et al., 2009; Hu et al., 2010). Große et al. (2007) investigated the cooling efficiency of simple and low-cost adiabatic microreactor with product recycle (loop reactor). The recycle stream in this reactor was externally cooled by a heat exchanger and returned into the reactor. The loop reactor was inherent safe (no runaway) and the mixing temperature of recycle stream and fresh feed could be simply regulated by recycle ratio. In order to make this system applicable, high 
conversion of reactants was needed, e.g. to avoid an expensive post-treatment of the ionic liquid to remove unconverted reactants. Another efficient system for passive heat removal was presented by Löwe et al. (2009). A heat pipe system, which transfers thermal energy by evaporation and condensation of a thermal fluid, provided a very efficient passive cooling without using cooling liquids (e.g. water) or other materials which can have an impact on ecology and wasting energy. Additionally, implementation of such heat pipes could contribute to cost reduction. The first prototype of plate stack microstructured heat exchanger was reported by Löb and his coworkers (Löb et al., 2007). The heat exchanger consisted of a stack of wet chemically etched plates with microchannel arrays. A microchannel array for the reaction mixture was surrounded by two microchannel arrays for the heat exchanger fluid. Imidazolium-based ionic liquid obtained with this prototype was almost colourless.

\subsection{Benefits of the ionic liquid synthesis within microfluidic devices}

In recent years, a number of articles have been published in which successful implementation of microreactor technology into ionic liquid synthesis was reported. Obtained ionic liquids were of high quality and, in certain process conditions, reaction times were reduced down to minutes as opposed to conventional batch systems in which reaction time was measured in hours, even days (Waterkamp et al., 2007; Renken et al., 2007).

Waterkamp et al. (2007) presented a way to intensify the solvent-free synthesis of 1-butyl-3methylimidazolium bromide ([BMIM]Br) from 1-methylimidazole (MeIm) and 1bromobutane $(\mathrm{BrBu})$, using a continuously operating microreactor system consisted of a vortex-type micromixer $(0.45 \mathrm{~mm}$ channel width) followed by series of three tubes with increasing inner diameter $(2-6 \mathrm{~mm})$. Each part of a tube was $6 \mathrm{~m}$ in lenght with total reaction volume of $306 \mathrm{~mL}$, allowing the production rate of $9.3 \mathrm{~kg}$ [BMIM] $\mathrm{Br}$ per day. In this reactor system, the strongly exothermic alkylation could be thermally controlled even at elevated temperatures, leading to high reaction rates in a solvent-free modus. The degree of process intensification achieved resulted in a more than twentyfold increase of the space-time-yield compared to the conventional batch process. In the experiment, a conversion of $95 \%$ could be obtained after $38 \mathrm{~min}$ at $85^{\circ} \mathrm{C}$. By the proposed simulation, the residence time demand could be reduced down to $10 \mathrm{~min}$ at wall temperatures of $105{ }^{\circ} \mathrm{C}$, leading to space-timeyield of $6.1 \mathrm{~kg} \mathrm{~h}^{-1} \mathrm{~L}^{-1}$.

Ranken et al. (2007) developed a first prototype of multiscale reactor system for the solventfree synthesis of ethylmethylimidazolium ethylsulfate ([EMIM] $\left.\left[\mathrm{EtSO}_{4}\right]\right)$ via alkylation of $\mathrm{N}$ methylimidazole with diethylsulfate (Figure 4). A microstructured reactor for efficient mixing of the reactants was the main part of the setup, followed by the section consisted of two tubular capillary reactors with diameters in the range of several millimeters. Microstructured reactor was composed of a stack of plates with parallel rectangular microchannels ( $1 \mathrm{~mm}$ wide and $0.65 \mathrm{~mm}$ high, $125 \mathrm{~mm}$ in length) with total inner volume of 10.8 $\mathrm{cm}^{3}$. Compared to capillary reactors operating at two different temperature levels, the space time was reduced from $4 \mathrm{~h}$ down to $4.6 \mathrm{~min}$. With this system the performance of the reaction could be increased by a factor of 50 . The throughput of the reactor system can be increased by simply numbering up of the system.

The limitation of a conventional batch process and the potential of continuous alkylation of 1-methylimidazole in microreactor rig with a micromixer followed by a capillary as residence time section were studied by Löb et al. (2007). A production rate of $0.21 \mathrm{~h}^{-1}$ of 


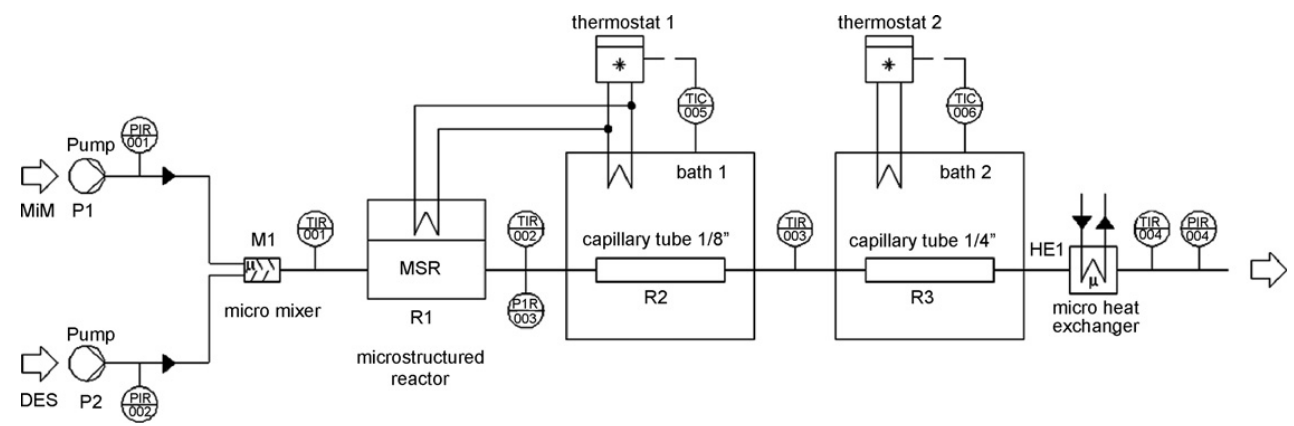

Fig. 4. Scheme of the experimental setup for [EMIM] $\left[\mathrm{EtSO}_{4}\right]$ synthesis. Adapted from Renken et al. (2007). Reproduced by permission of Elsevier.

almost colorless ionic liquid could be reached in a microreactor rig with a reactor inner volume of only $7.5 \mathrm{~mL}$. Therewith a reduction of reaction time from some hours for the current batch process to only $2.2 \mathrm{~min}$ was conducted.

Waterkamp and his group also tested the influence of reaction temperature and flow rate on the colorization of the product in solvent free synthesis of 1-butyl-3-methylimidazolium bromide ([BMIM]Br) in capillary reactor. By using microreactor technology they have studied to which extent intensified mass transfer can be used as a tool to control side product formation in the form of colored impurities. It was concluded that temperature and flow rate at which the alkylation is governed both influence the product colorization. The temperature increase (at identical flow rate), as well as flow rate decrease (at identical temperature) led to more intensive colorization. This effect was explained by enhanced transport velocity of 1-methylimidazole from the product phase to the alkylating agent phase, leading to higher overall rate of the main reaction and reducing the contact time of the 1-methylimidazole with itself. Even at harsh temperature conditions, meaning a reaction temperature of $145^{\circ} \mathrm{C}$, a lowly colored ionic liquid could be produced by increasing the flow velocity (Waterkamp et al., 2009).

Even though there are numerous reports regarding the batch laboratory-scale synthesis of ionic liquids using microwave irradiation under solvent-free conditions, only few articles regarding microwave-assisted microreactor processing $\left(\mu^{2}\right)$ were published on this topic. Minrath et al. (2008) investigated the synthesis of 1-methyl-3-hexylimidazolium bromide under different continuous procedures, using the micro-wave irradiation. A micromixertubular $(\mathrm{d}<0.5 \mathrm{~mm})$ reactor was used to perform the reaction with microwave heating. As a result it can be turned out that a low microwave energy-supply, partially less than $50 \mathrm{~W}$, and a short residence time of approx. $10 \mathrm{~min}$ led to high conversion and selectivity of the targeted product. Also at higher microwave energies $(>200 \mathrm{~W})$, the residence time could be shortened to less than $2 \mathrm{~min}$.

An interesting novel and cheaper method for ionic liquid synthesis by modified Radziszewski reaction was recently published by Zimmermann et al. (2010). They demonstrated that water-soluble 1,3-dialkylimidazolium-based ionic liquids could be produced in high yields and purities, starting from available and relatively cheap precursors - monoalkylamines, glyoxal, formaldehyde, and mineral or organic acids (Figure 5). The synthesis of 1,3-dibutylimidazolium acetate ([dBIM][OAc]) and 1,3-dibutylimidazolium chloride $([\mathrm{dBIM}] \mathrm{Cl})$ was achieved by continuous production in a microreactor. The solution 
of formaldehyde and acid ( $\mathrm{HCl}, \mathrm{HOAc}$ ) was mixed with $n$-butylamine within micromixer (internal volume $0.06 \mathrm{~mL}$ ), and directed into the residence time unit. After passing through residence time unit, the reaction mixture was brought in contact with glyoxal in a second mixer and reacted in a second residence time unit. All sections of the set-up were under pressure and temperature control. In comparison to the modified Radziszewski reaction in batch mode, the reaction times were reduced by factor 3 and 6 for [dBIM]Cl and [dBIM][OAc], respectively, while the yields increased slightly.

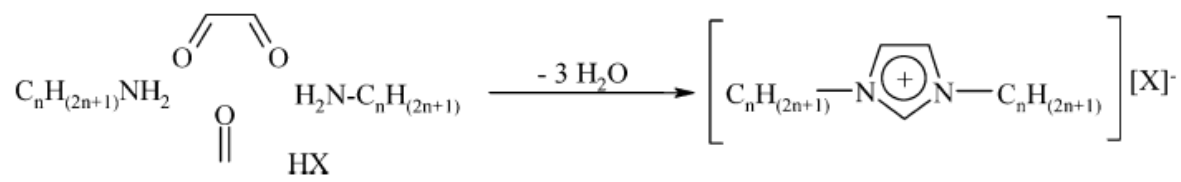

Fig. 5. Modified Radziszewski reaction. Adapted from Zimermann et al. (2010). Reproduced by permission of the American Chemical Society.

\section{4. (Bio)catalysis in ionic liquids within microfluidic devices}

Ionic liquids have been employed as the reaction media for a wide range of (bio)catalytic processes, as catalysts or as (bio)catalyst-supports. These modern solvents have been shown to possess a significant effect on the stabilization of charged intermediates in chemical catalytic processes, as well as on enzymes' stability. Some ionic liquids have been shown to be by far the best non-aqueous media for biocatalytic processes due to their positive influences on enzyme stability and activity, as well as on the enantioselectivity of the reactions catalyzed by them (Park \& Kazlauskas, 2003). When the right ionic liquid is chosen for a given reaction, it can lead not only to enhanced selectivity, yield or reaction rate, but it also improves the result of the work-up, from product separation (extraction/distillation) to recycling of the system ionic liquid/(bio)catalysts (Dyson et al, 2003; Pârvulescu \& Hardacre, 2007; van Rantwijk \& Sheldon, 2007). Separation of products from ionic liquid and ionic liquid recovery can be accomplished by distillation of product (if the product is sufficiently volatile), extraction with supercritical $\mathrm{CO}_{2}$, or simple phase separation (if the product is immiscible in the ionic liquid) (Cornils, 1999).

Implementation of microreactor technology, together with the use of ionic liquids as a replacement for conventional organic solvents, into (bio)catalysis could be a significant alternative to conventional (bio)catalytic processes, considering advantages of both approaches. Tailor-made concept of environmentally friendly ionic liquids to improve their properties for certain catalyzed reaction (enzyme activity/stability, solubility of the substrates, stabilization of charged intermediates), together with the benefits of highthroughput reaction optimization, should be considered as a new promising "symbiosis" for the production of commercially important chemicals.

\subsection{Chemical catalysis}

Ionic liquids have been thoroughly investigated as (co)solvents in most types of catalytic reactions such as rhodium and ruthenium catalyzed hydrogen addition and rearrangement reactions (Chauvin et al., 1995; Dyson et al., 1999), C-C and C-O cleavage reactions (Green et al., 2000; Song et al., 2000), and C-C or C-heteroatom coupling reactions (Earle et al., 1999; Zulfigar \& Kitazume, 2000). In these reaction systems, ionic liquids can be used as solvent or 
both solvent and catalyst in monophasic systems. In biphasic systems, ionic liquid can be used as a phase for embedding catalyst while substrate/product remains dissolved in a second phase. Moreover, the anion of the ionic liquid can also act as ligand for the homogeneous catalysis, both in monophasic and biphasic systems (Sheldon, 2001). Even though the monophasic catalysis poses a lot of advantages (e.g. availability of the reagents to the catalyst), catalysis in biphasic mode is becoming very popular due to easy separation of substrate/product and catalyst recovery (Welton, 1999). Disadvantage of traditional aqueous-organic biphasic systems is low solubility of the catalyst and/or organic substrates in water, causing low reaction rates. When used in place of water, ionic liquids can form ionic liquid-organic solvent systems without suffering from these limitations (Zhao et al., 2002).

Applications of microreactors to biphasic catalytic reactions constitute a topic of interest. The benefits of having an exceedingly high surface-to-volume ratio and efficient mass-transfer in microchannels have led many researchers to study continuous flow systems using microreactors for catalytic reactions. The excellent mass transfer characteristics within and between the catalyst carrier phase and reaction medium, together with the minimal catalytic pore diffusion resistances at the micrometer scale, make such biphasic catalysis an attractive alternative to conventional catalysis operation (Wießmeier, 1996; Rahman et al., 2006).

Several authors reported on successful Pd-catalyzed cross coupling reactions in ionic liquids within a microfluidic devices, such as Sonogashira reactions (Fukuyama et al., 2002; Rahman et al., 2006) and Mizoroki-Heck reactions (Liu et al., 2004). Fukuyama and his group conducted the first example of a homogeneous metal-catalyzed reaction in a microreactor (Figure 6). The $\mathrm{PdCl}_{2}\left(\mathrm{PPh}_{3}\right)_{2}$-catalyzed Sonogashira coupling of terminal alkynes with aryl or vinyl halides in 1-butyl-3-methylimidazolium hexafluorophosphate ([BMIM][PF 6$]$ ) as the reaction medium and catalyst-support in the absence of a copper salt was successfully performed, in good to high yields. Sonogashira coupling is typically carried out in organic solvents, such as toluene, tetrahydrofurane, and dimethylsulfoxide, with a palladium catalyst, a copper (I) cocatalyst, and stoichiometric amount of amine base. The advantage of ionic liquid as a reaction media was in terms of catalyst recycling, since the organic products could be readily separated from the transition metal catalysts dissolved in the ionic liquids by simple extraction with a conventional organic solvent. Reaction was also performed in a microflow system in conjunction with a micromixer having interdigitated channels $(0.04$ $\mathrm{mm}$ width and $0.2 \mathrm{~mm}$ depth) to ensure the continuous production of acetylenic compounds. The coupling product diphenylacetylene was formed and was easily isolated from the mixture by extraction with hexane/water (93\% yield). The resulting ionic liquid containing the Pd catalyst could be successfully reused for several times with only a slight loss in its activity (Fukuyama et al., 2002).

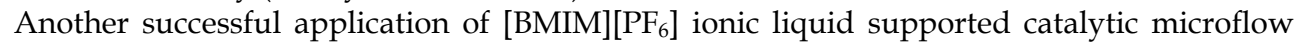
reactions for Pd-catalyzed carbonylative Sonogasnira coupling of aryl iodides and phenylacetylene was reported by Rahman et al. (2006). Ionic liquid containing Pd catalysts, $\mathrm{CO}$ and the substrates were mixed successively, in different micromixers (channel diameter $=1$ and $0.40 \mathrm{~mm}$ ), and then pumped as a multiphase (ionic liquid-substrate-CO) into heated capillary tube reactor acting as a residence time unit $(\mathrm{V}=14.1 \mathrm{~mL})$. It was found that $\mathrm{Pd}$ catalyzed production of solely the acetylenic ketones in ionic liquids, when conducted in conjunction with a microreactor, preceded efficiently with superior selectivity and higher yields compared to the conventional batch system, even at low CO pressures. Authors suggested that this improvement in selectivity and yield was the result of a large interfacial 

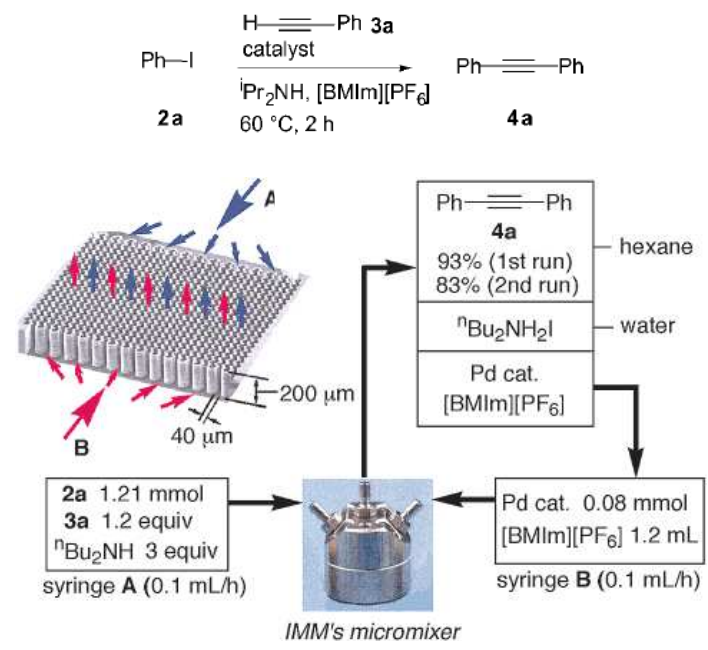

Fig. 6. Sonogashira reaction in a microflow system. Iodobenzene (2a), phenylacetylene (3a) and amine base were mixed in the micromixer. The coupling product (4a) was formed and was easily isolated by extraction with hexane/water. Adapted from Fukuyama et al. (2002). Reproduced by permission of the American Chemical Society.

area-to-volume ratio or efficient $\mathrm{CO}$ diffusion through ionic liquid in microflow system that couldn't be obtained in standard batch reactor.

An example of a microflow continuous palladium-catalyzed Mizoroki-Heck coupling between iodobenzene with butyl acrylate, in combination with continuous microextraction/catalyst recyclation was reported by Liu and coworkers (Liu et al., 2004). Their reaction was catalyzed by a $\left[\mathrm{Pd}\left(\mathrm{PPh}_{3}\right) \mathrm{Cl}_{2}(\mathrm{BMIM})\right]$ carbene complex, which was immobilized in the low-viscosity ionic liquid 1-butyl-3-methylimidazolium bis(trifluoromethylsulfonyl)imide ([BMIM] $\left.\left[\left(\mathrm{CF}_{3} \mathrm{SO}_{2}\right)_{2} \mathrm{~N}\right]\right)$. Using automated microflow apparatus (Figure 7), iodobenzene, butyl acrylate, and tripropylamine were introduced from one inlet of the micromixer (channel width $0.1 \mathrm{~mm}$, inner volume $2 \mathrm{~mL}$ ), and the ionic liquid containing the Pd catalyst was introduced from the other inlet. Two solutions were mixed in the microreactor and were pumped into the temperature controlled residence time unit.

The ionic liquid solution exiting from the microflow reaction apparatus was introduced into a T-shaped static micromixer (channel diameter $0.3 \mathrm{~mm}$ ), where the ammonium salt (byproduct) was washed by mixing with aqueous solution of $\mathrm{NaOH}$. The mixture was then mixed by another T-shaped static micromixer, where hexane was introduced to extract the product. On standing in the Y-shaped glass flask, the resulting mixture separated into three phases, a hexane layer containing the product and tripropylamine, an aqueous layer containing the inorganic salt, and the ionic liquid layer containing the Pd catalyst. The ionic liquid in the bottom layer was pumped back to container for recycling the Pd catalyst. The coupling product, butyl cinnamate, was produced in an overall yield of $80 \%(115.3 \mathrm{~g}, 10 \mathrm{~g}$ $\mathrm{h}^{-1}$ ). With an originally developed microextraction/catalyst recycling system, the ionic liquid containing Pd catalyst could be continuously recycled to provide a total of $115.3 \mathrm{~g}$ $\left(80 \%, 10 \mathrm{~g} \mathrm{~h}^{-1}\right)$. 

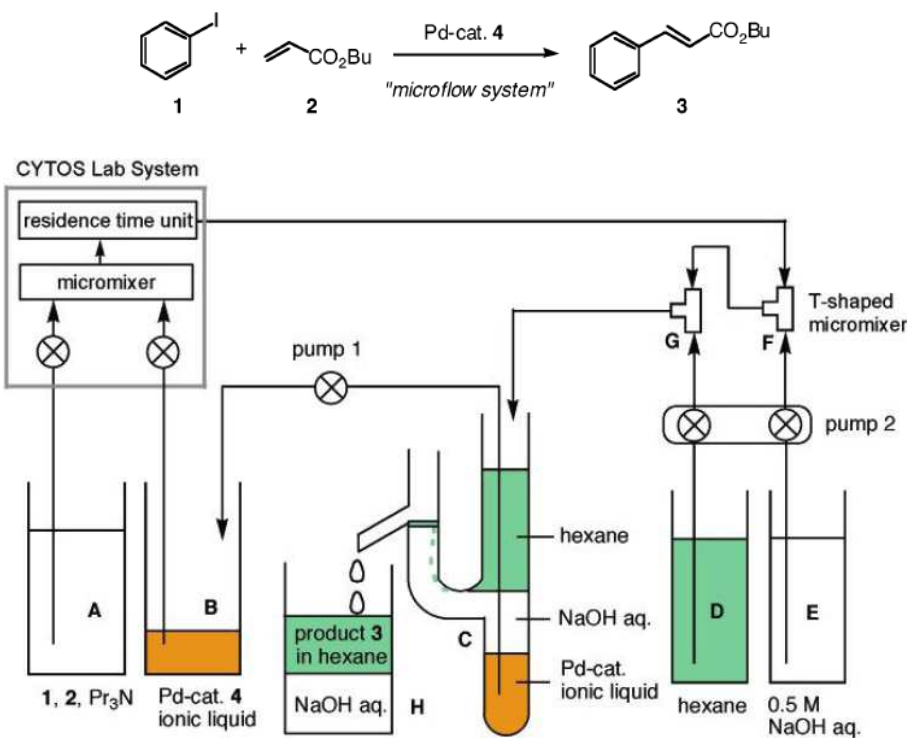

Fig. 7. Detailed continuous workup process of coupling between iodobenzene with butyl acrylate with flow workup/catalyst recycling system. Adapted from Liu et al. (2004). Reproduced by permission of the American Chemical Society.

The first study of the epoxidation of cyclohexene in a silicon-based microreactor was reported by Basheer et al. (2006). Due to a low solubility of cyclohexene in the phosphate buffer reaction media, ionic liquid 1-butyl-3-methylimidazolium tetrafluoroborate ([BMIM] $\left.\left[\mathrm{BF}_{4}\right]\right)$ was introduced $(0.5 \% \mathrm{v} / \mathrm{v})$ to the buffer solution. The performance of four various types of catalysts such as Schiff-base and reduced Schiff-base complexes of $\mathrm{Cu}$ (II) and $\mathrm{Mn}$ (II) complexes were investigated. The T-shaped microfluidic channel was filled with phosphate buffer solution of ionic liquid and $5 \%$ of the Schiff catalysts. The reactant was introduced to the microchannel, driven by a difference in the electric potential between the inlet and the outlet of the microchannel. Catalytic activity and yields were found to be relatively high for the $\mathrm{Cu}$ (II) complexes as compared with those obtained with conventional bulk scale epoxidation.

Recently, ionic liquid was employed in a structured catalytic wall microreactor suitable for highly exothermic heterogeneous gas/solid reactions (Kiwi-Minsker et al., 2010). $\mathrm{Pd}^{\circ}$ nanoparticles embedded in an ionic liquid and deposited on activated carbon fibers with high specific surface area were used as a structured catalyst. The system allowed flowing of the reaction mixture through an empty micro-slit above the structured catalyst placed along the wall of the reactor (Figure 8). Selective acetylene hydrogenation was tested as a model of highly exothermic reaction with temperature sensitive catalyst. The temperature was easily controlled without hot spot formation, confirming the efficient heat exchange in the microreactor. The reaction performance was optimized by varying flow rates and temperatures. The selectivity of $\sim 70 \%$ was obtained at conversion of $96.5 \%$ under steadystate conditions at $200 \circ \mathrm{C}$ without any catalyst deactivation over $10 \mathrm{~h}$ on stream. 
(a)



(b)

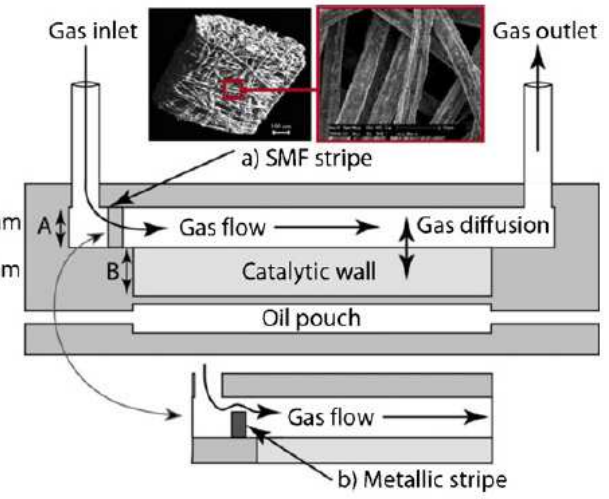

Fig. 8. a) 3D representation of the aluminum plates fixing the ionic liquid-supported catalyst, b) 2D scheme of the structured catalytic wall microreactor. Adapted from KiwiMinsker et al. (2010). Reproduced by permission of Elsevier.

\subsection{Biocatalysis}

Enzymatic microreactors are becoming a useful tool for organic synthesis, together with chemical analysis and kinetic studies of catalytic reactors (Urban et al., 2006; Fernandes, 2009). Additionally, these systems have the potential for introduction into industrial-scale synthesis. From the aspect of the use of ionic liquids as reaction media within microreactors, the ability of external numbering-up is of great importance, due to high viscosity of ionic liquids and problems regarding mass and heat transfer in large scale bioreactors. This mode of scaling up provides good adjustability and control over the process, due to repetition of the fluidic path while the transport properties and hydrodynamics are preserved (Hessel et al., 2004a). Biocatalytic synthesis in microreactors is still a relatively new field and most examples therefore describe the proof of concept with known enzymatic transformations. However, because of the advantages that have been clearly demonstrated, biocatalytic microreactors are also expected to be used for explorative research purposes.

An example of highly efficient Candida antarctica lipase B-catalyzed synthesis of isoamyl acetate in 1-butyl-3-methylpyridinium dicyanamide ([BMPYR][dca])/ $n$-heptane two-phase system within continuously operated glass microreactor was recently published (Pohar et al., 2009). The microreactor had one outlet and three separate $\psi$-shaped inlet channels, one for the inflow of ionic liquid phase with dissolved enzyme and isoamyl alcohol, the other for ionic liquid with dissolved acetic anhydride together with aqueous enzyme solution, and the third for the inflow of $n$-heptane. Furthermore, a $3 \mathrm{~m}$ long polytetrafluoroethylene tube with the inner diameter of $0.245 \mathrm{~mm}$ was fitted at the exit of the glass part of the microreactor to provide longer residence times for the reaction. A [BMPYR][dca] $n$-heptane biphasic system within microfluidic system was found to be highly efficient as it showed an almost three-fold increase in the reaction rate as compared to an intensively mixed batch operation, resulting in far better productivity than any, reported so far. This was mainly a consequence of efficient reaction-diffusion dynamics in the microchannel system, where the developed flow pattern comprising of intense emulsification provided a large interfacial area for the reaction and simultaneous product extraction (Figure 9). 


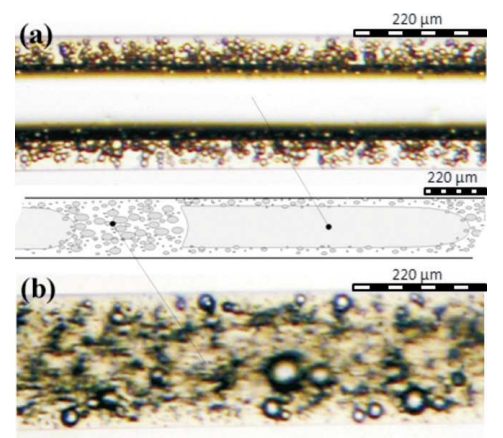

Fig. 9. Schematic presentation with photographic details of the developed flow pattern within the major part of the microreactor. (a) A long slug of $n$-heptane with concave tail surrounded with small droplets of $n$-heptane and (b) fine dispersion between the two neighboring $n$-heptane slugs. Adapted from Pohar et al. (2009). Reproduced by permission of the American Chemical Society.

A functional, easily assembled, operated and cleaned microbioreactor packed with immobilized Candida antarctica lipase B (Novozyme 435) was recently developed by Pohar et al. (2010). So far, microbioreactor was used for studying continuous mode ester synthesis within bis(trifluoromethylsulfonyl)imide - based ionic liquid media. Ionic liquid containing substrates was pumped into the microbioreactor at various flow rates, and at the outlet of the reactor the product was collected and analyzed. With fully adjustable length, width and depth, the developed packed bed microbioreactor was proven to be a very successful and versatile tooling for biocatalytic reactions such as isoamyl acetate or butyl butyrate synthesis (Cvjetko et al, 2010; Pohar et al., 2010).

\section{Downstream processing employing ionic liquids within microfluidic devices}

The quality of any industrial product is highly dependent on the correct selection of downstream processes and purification methods. Also, downstream processing costs might require the majority of the total production costs. The short molecular diffusion distance in miniaturized devices and the large specific interface allow very efficient separation. Since microchannel devices provide better control of process conditions, improved safety, and speed to market from laboratory development to commercial manufacturing, these devices are extremely useful for purification of reagents, solvents, intermediates, or final products (Žnidaršič-Plazl \& Plazl, 2007). Microfluidic technology also allows the design and operation of analytical devices for high-throughput application such as selective separation and analysis of biomolecules and chemicals (Sato et al., 2003). Furthermore, the integration of reaction with in situ product isolation within microchannel system has already been proved to substantially increase productivity of (bio)catalyzed processes (Cauwenberg et al.; 1999, Huh et al., 2006; Pohar et al., 2009)

The two-phase characteristics of ionic liquid-organic solvent system also pave the way for the use in microreactors. Extraction of products at the micro scale by the implementation of ionic liquids gives rise to the possibility of the convenient separation of synthetic goods, plastics and metals. Besides, ionic liquids offer the specificity required to separate similar 
compounds from each other (Wasserscheid \& Eichmann, 2001). Several authors reported on the use of ionic liquids for extraction of biomolecules (Pei et al., 2009; Ge et al., 2010; Tomé et al., 2010), aromatic compound (Meindersma et al., 2005; Zhou et al., 2009), metals (Wei et al., 2003; Germani et al., 2007; Yoon et al., 2010; Egorov et al., 2010), and organic compounds (Marták \& Schlosser, 2007; Simoni et al., 2010). The use of ionic liquids for enantioselective extraction was studied as well (Huh et al., 2006; Tang et al., 2010).

At the time, rare cases of simultaneous reaction/extraction in two-phase systems containing ionic liquids within microfluidic devices confirm the potential for further prosperity of this field. Huh et al. (2006) were the first to investigate the possibility of ionic liquid-supported microfluidic separation using enzymatic reaction. In general, the three-phase (water/ionic liquid/water) flow in the microchannel was formed by controlling the flow rate of the ionic liquid phase (Figure 10). The feeding phase consisted of ethanol, racemic ibuprofen, buffer and Candida rugosa lipase (CRL) that catalyzed esterification of (S)-ibuprofen rather than (R)ibuprofen. By combining lipase-catalyzed reaction and fast selective transport of (S)ibuprofen through 1-hexyl-3-methylimidazolium hexafluorophosphate ([BMIM][PF 6$]$ membrane, a successful enantioselective separation of $(S)$-ibuprofen from racemic mixture was achieved. In receiving phase, Porcine pancreas lipase (PPL) catalyzed ester hydrolysis to produce starting ester, (S)-ibuprofen, and ethanol. The high efficiency of this microfluidic device was the consequence of the large area between the aqueous phase and the ionic liquid phase compared to the conventional bulk processes. Therefore, this microfluidic device with the ionic liquid phase could become suitable portable system with decreased reagent requirements for the selective and rapid separation of biologically functional molecules from the racemic mixtures.

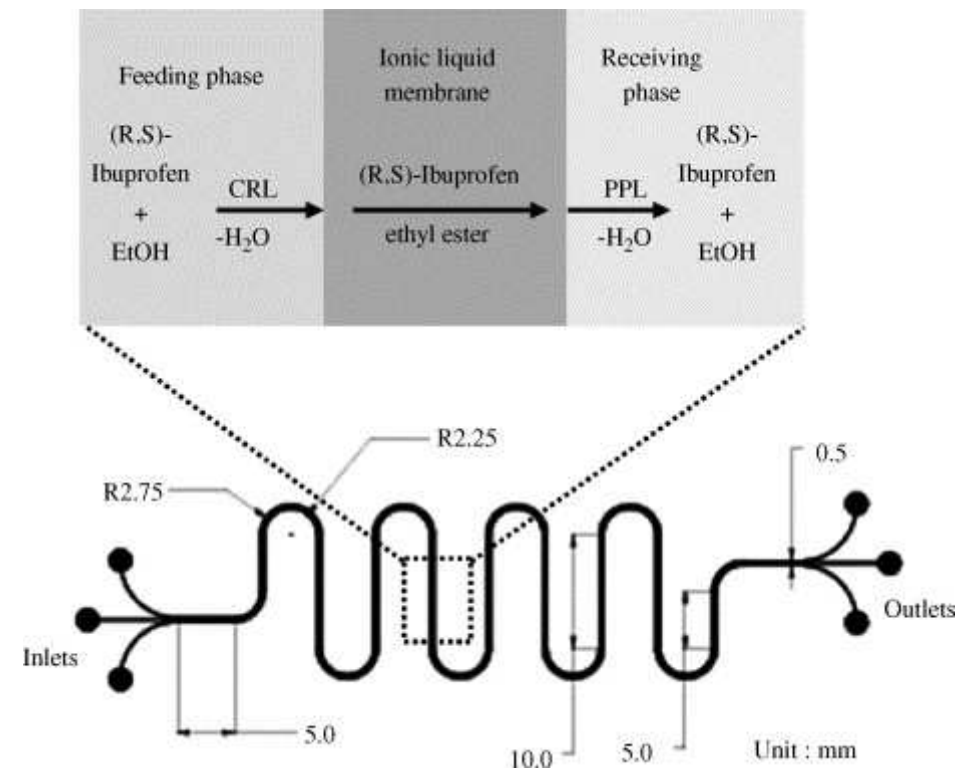

Fig. 10. Schematic drawing of the microfluidic channel and the enantioselective transport of (S)-ibuprofen through the ionic liquid in the microfluidic device. Adapted from Huh et al. (2006). Reproduced with permission. Copyright Elsevier, 2006. 
A successful lipase-catalyzed synthesis of isoamyl acetate in ionic liquid/ $n$-heptane twophase system, presented in the previous section (Pohar et al., 2009), also based on the integration of synthesis and product recovery within microfluidic device. Since the majority of the product was accumulated in $n$-heptane, while enzyme stayed suspended in [BMPYR][dca], which was separated from $n$-heptane at the exit from the microchannel, this modus provided the efficient simultaneous product separation and ionic liquid/enzyme recycling.

Recently, an integrated system consisting of a microbioreactor packed with immobilized Candida antarctica lipase B and a miniaturized separator was developed for performing biocatalytic reactions in a continuous mode (Pohar et al., 2010). In order to isolate the product from the ionic liquid media after the reaction in a microbioreactor, a miniaturized continuous evaporator was designed. Since ionic liquids have a very high boiling point compared to solutes (substrates/products), they could be effectively removed with evaporation within the microchannel. The use of a continuous microevaporator was shown to be highly effective for the isolation of a product (butyl butyrate) from the chosen ionic liquid, as well as for the cleaning of ionic liquid, which could be further reused (Pohar et al., 2010).

\section{References}

Basheer, C., Vetrichelvan, M., Suresh, V., Lee, H. K. (2006). Ionic-liquid supported oxidation reactions in a silicon-based microreactor. Tetrah. Lett., 47, 6, (February 2006) 957961, ISSN 0040-4039

Böwing, A. G. \& Jess, A. (2005). Kinetics of single- and two-phase synthesis of the ionic liquid 1-butyl-3-methylimidazolium chloride. Green Chem., 7, 4, (March 2005) 230235, ISSN 1463-9262

Cauwenberg, V., Vergossen, P., Stankiewicz, A., Kierkels, H. (1999). Integration of reaction and separation in manufacturing of pharmaceuticals: Membrane-mediated production of S-ibuprofen. Chem. Eng. Sci. 54, 10, (May 1999) 1473-1477, ISSN 00092509

Chauvin, Y., Mussmann, L., Olivier, H. (1996). A novel class of versatile solvents for twophase catalysis: hydrogenation, isomerization, and hydroformylation of alkenes catalyzed by rhodium complexes in liquid 1,3-dialkylimidazolium salts. Angew. Chem. Int. Ed. Engl. 34, 23-24, (January 1996) 2698-2700, ISSN 0570-0833

Cornils, B. (1999). Bulk and fine chemicals via aqueous biphasic catalysis. J. Mol. Catal. A, 143, 1-3, (July 1999) 1-10, ISSN 1381-1169

Cravotto, G., Cintas, P. (2006). Power ultrasound in organic synthesis: moving cavitational chemistry from academia to innovative and large-scale applications. Chem. Soc. Rev., 35, 2, (October 2005) 180-196, ISSN 1460-4744

Cvjetko, M., Vorkapić-Furač, J., Pohar, A., Žnidaršič-Plazl, P. (2010). Synthesis of ionic liquids and their use as solvents for biocatalysis in microreactors. Proceedings of the International thematic conference "Implementation of microreactor technology into biotechnology", September 29-30, 2010, Ljubljana, Slovenia, Faculty of Chemistry and Chemical Technology, Ljubljana: ISBN 978-961-6756-20-4 
Dyson, P. J. Ellis, D. J., Parker, D. G., Welton, T. (1999). Arene hydrogenation in a room temperature ionic liquid using a ruthenium cluster catalyst. Chem. Commun., 25-26. ISSN 1359-7345

Dyson, P. J., Ellis, D. J., Henderson, W., Laurenczy, G. (2003). A comparison of rutheniumcatalysed arene hydrogenation reactions in water and 1-alkyl-3-methylimidazolium tetrafluoroborate ionic liquids. Adv. Synth. Catal., 345, 1-2, (January 2003) 216-221, ISSN 1615-4150

Dyson, P. J., Geldbach, T. J. (2005). Metal catalysed reactions in ionic liquids, in catalysis by metal complexes, volume 29, Springer, ISBN-10 1-4020-3915-8, Dordrecht, the Netherlands.

Earle, M.J., McCormack, P.B., Seddon, K.R. (1999). The first high yield green route to a pharmaceutical in a room temperature ionic liquid. Green Chem., 2, 6, (October 2000) 261-262, ISSN 1463-9262

Egorov, V. M., Djigailo, D. I., Momotenko, D. S., Chernyshov, D. V., Torocheshnikova, I. I., Smirnova, S. V., Pletnev, I. V. (2010). Task-specific ionic liquid trioctylmethylammonium salicylate as extraction solvent for transition metal ions. Talanta, 80, 3, (January 2010) 1177-1182, ISSN 0039-9140

Ehrfeld W., Hessel V., Löwe H. (2000). Microreactors: new technology for modern chemistry, Wiley-VCH, ISBN 978-3-527-29590-6, Weinheim, Germany.

Fernandes, P. (2010). Miniaturization in biocatalysis. Int. J. Mol. Sci., 11, 3, (March 2010) 858879, ISSN 1422-0067

Fukuyama, T., Shinmen, M., Nishitani, S., Sato, M., Ryu, I. (2002). A copper-free Sonogashira coupling reaction in ionic liquids and its application to a microflow system for efficient catalyst recycling. Org. Lett., 2002, 4, 10, (April 2002) 1691-1694, ISSN 15237060

Ge, L., Wang, X., Tan, S. N., Tsai, H. H., Yong, Y. W. H., Hua, L. (2010). A novel method of protein extraction from yeast using ionic liquid solution, Talanta, 81, 4-5, (June 2010) 1861-1864, ISSN 0039-9140

Germani, R., Mancini, M. V., Savelli, G., Spreti, N. (2007). Mercury extraction by ionic liquids: temperature and alkyl chain length effect. Tetrahedron Lett., 48, 10, (March 2007) 1767-1769, ISSN 0040-4039

Gonzales, M. A., Ciszewski, J. T. (2009). High conversion, solvent Free, continuous synthesis of imidazolium ionic liquids in spinning tube-in-tube reactors. Org. Process Res. Dev., 13, 1, (December 2008) 64-66, ISSN 1083-6160

Gorman, J. (2001). Faster, better, cleaner? New liquids take aim at old-fashioned chemistry. Sci. News, 160, 10, (September 2001), 156-158, ISSN 1016-1503

Green, L., Hemeon, I., Singer, R.D. (2000). 1-Ethyl-3-methylimidazolium halogenoaluminate ionic liquids as reaction media for the acylative cleavage of ethers. Tetrahedron Lett., 41, 9, (February 2000) 1343-1346, ISSN 0040-4039

Hessel, V., Löwe, H., Schönfeld, F. (2004b). Micromixers - a review on passive and active mixing principles. Chem. Eng. Sci., 60, 8-9, (April-May 2005) 2479-2501, ISSN 00092509

Hessel, V., Hardt, S., Loewe, H. (2004a). Chemical Micro Process Engineering - Fundamentals, Modelling and Reactions, Wiley-VCH, ISBN 3-527-30741-9, Mainz, Germany

Hessel, V., Löb, P., Löwe, H. (2005). Development of microstructured reactors to enable chemistry rather than subduing chemistry around the reactor - potentials of 
microstructured reactors for organic synthesis. Curr. Org. Chem., 9, 8, (May 2005) 765-787, ISSN 1385-2728

Hu, S., Wang, A., Löwe, H., Li, X., Wang, Y., Li, C., Yang, D. (2010). Kinetic study of ionic liquid synthesis in a microchannel reactor. Chem Eng J., 162, 1, (August 2010) 350354, ISSN 1385-8947

Huh, Y. S., Jun, Y., Hongb, Y. K., Honga, W. H., Kima, D. H. (2006). Microfluidic separation of (S)-ibuprofen using enzymatic reaction. J. Mol. Catal. B: Enzym., 43, 1-4, (December 2006), 96-101, ISSN 1381-1177

Jähnisch, K., Hessel, V., Löwe, H., Baerns, M. (2004). Chemistry in microstructured reactors. Angew. Chem. Int. Ed., 43, 4, (January 2004) 406-446, ISSN 1433-7851

Kiwi-Minsker, L., Ruta, M., Eslanloo-Pereira, T., Bromley, B. (2010). Structured catalytic wall microreactor for efficient performance of exothermic reactions. Chem. Eng. Process., 49, 9, (September 2010) 973-978, ISSN 0255-2701

Liu, S., Fukuyama, T., Sato, M., Ryu, I. (2004). Continuous microflow synthesis of butyl cinnamate by a Mizoroki-Heck reaction using a low-viscosity ionic liquid as the recycling reaction medium. Org. Proc. Res. Dev., 8, 3, (April 2004) 477-481, ISSN 1083-6160

Löb, P., Hessel, V., Balon-burger, M., Hang, T., Illg, T., Menges, G., Hofmann, C., Krtschil, U., Uerdingen, M. (2007). Ionic Liquid synthesis in continuous microreactor using multiscale approach, Proceedings of the 1 st international congress on green process engineering, pp. 1-9, 2-910239-68-3, Toulouse, France, 24-26 april 2007, Ed. SFGP, Paris, France

Loupy, A. (2006). Microwaves in organic synthesis; Wiley-VCH, ISBN 9783527601776, Weinheim, Germany.

Lowe, H., Axinte, R. D., Breuch, D., Hofmann, C. (2009). Heat pipe controlled synthesis of ionic liquids in microstructured reactors. Chem. Eng. Jour., 155, 1-2, (December 2009) 545-550, ISSN 1385-8947

Marták, J., Schlosser, Š. (2007). Extraction of lactic acid by phosphonium ionic liquids. Sep. Purif. Technol., 57, 3, (November 2007), 483-494, ISSN 1383-5866

Meindersma, G. W., Podt, A., de Han, A. B. (2005). Selection of ionic liquids for the extraction of aromatic hydrocarbons from aromatic/aliphatic mixtures. Fuel Process. Technol., 87, 1, (December 2005) 59-70, ISSN 0378-3820

Mills, P. L., Quiram, D. J., Ryley, J. F. (2007). Microreactor technology and process miniaturization for catalytic reactions. A perspective on recent developments and emerging technologies. Chem. Eng. Sci., 62, 24, (December 2007) 6992-7010, ISSN 0009-2509

Minrath, I., Beck, M., Pitton, D., Zankl, F., Loewe, H. $\mu^{2}$ - Microwave assisted microreactor processing: synthesis of ionic liquids, Proceedings of the "10 th International Conference on Microreaction Technology, IMRET 10", 06 -10 April, 2008, New Orleans, LU.

Park, S., Kazlauskas, R. J. (2003). Biocatalysis in ionic liquids-advantages beyond green technology. Curr. Opin. Biotechnol., 2, 14, (August 2003) 432-437, ISSN 0958-1669

Pârvulescu, V. I., Hardacre, C. (2007). Catalysis in ionic liquids. Chem. Rev., 107, 6, ISSN 2615-2665

Pavlou, F. (2009). Microreactor technology: Is the industry ready for it yet? Pharm. Tech. Europe, 21, 10, (October 2009) ISSN 0164-6826 
Pei, Y., Wanga, J., Wu, K., Xiaopeng, X., Lu, X. (2009). Ionic liquid-based aqueous two-phase extraction of selected proteins. Sep. Purif. Technol., 64, 3, (January 2009) 288-295, ISSN 1383-5866

Pohar, A., Plazl, I. (2008) Laminar to turbulent transition and heat transfer in a microreactor : mathematical modeling and experiments. Ind. Eng. Chem. Res, 47, 19, (August 2008) 7447-7455, ISSN 0888-5885.

Pohar, A., Plazl, I. (2009). Process intensification through microreactor application. Chem. Biochem. Eng. Q., 23, 4, (December 2009) 537-544, ISSN 0352-9568

Pohar, A., Plazl, I., Žnidaršič-Plazl P. (2009). Lipase-catalyzed synthesis of isoamyl acetate in an ionic liquid/ $n$-heptane two-phase system at the microreactor scale. Lab Chip, 9, 23, (December 2009) 3385 - 3390, ISSN 1473-0189

Pohar, A., Žnidaršič-Plazl, P., Plazl, I. (2010). Integrated process of transesterification within a microchannel system. Proceedings of the International thematic conference "Implementation of microreactor technology into biotechnology", September 29-30, 2010, Ljubljana, Slovenia, Faculty of Chemistry and Chemical Technology, Ljubljana: ISBN 978-961-6756-20-4

Poole, C. F., Pool, S. K. (2010) Extraction of organic compounds with room temperature ionic liquids. J. Chrom. A, 1217, 16, (April 2010) 2268-2286, ISSN 0021-9673

Rahman, T., Fukuyama, T., Kamata, N., Sato, M., Ryu, I. (2006). Low pressure Pd-catalyzed carbonylation in an ionic liquid using a multiphase microflow system. Chem. Commun., 21, (June 2006) 236-2238, ISSN 4995-4997

Renken, A., Hessel, V., Löb, P., Miszczuk, R., Uerdingen, M. \& Kiwi-Minsker, L. (2007). Ionic liquid synthesis in a microstructured reactor for process intensification. Chem. Eng. Process., 46, 9, (September 2007) 840-845, ISSN 0255-2701

Sabotin, I., Tristo, G., Bissacco, G., Junkar, M., Valentinčič, J. (2010). Staggered Herringbone Mixer designed for micro EDM milling. Proceedings of the International thematic conference "Implementation of microreactor technology into biotechnology", September 29-30, 2010, Ljubljana, Slovenia, Faculty of Chemistry and Chemical Technology, Ljubljana: ISBN 978-961-6756-20-4

Sato, K., Hibara, A., Tokeshi, M., Hisamoto, H., Kitamori, T. (2003). Microchip-based chemical and biochemical analysis systems. Adv. Drug Deliv.Rev., 55, 3, (February 2003) 379-391, ISSN 0169-409X

Sheldon, R. (2001). Catalytic reactions in ionic liquids. Chem. Comm., 23, (December 2001) 2399-2407, ISSN 4995-4997

Simoni, L. D., Chapeaux, A., Brennecke, J. F., Stadtherr, M. A. (2010). Extraction of biofuels and biofeedstocks from aqueous solutions using ionic liquids. Comput. Chem. Eng., 34, 9, (September 2010) 1406-1412, ISSN 0098-1354

Song, C.E., Oh, C. R., Roh, E.J., Choo, D.J. (2000). Cr(salen) catalysed asymmetric ring opening reactions of epoxides in room temperature ionic liquids. Chem. Commun., 32, 1, (January 2001) 1743-1744, ISSN 1359-7345

Tang, F., Zhang, Q., Ren, D., Nie, Z., Liu, Q., Yao, S. (2010). Functional amino acid ionic liquids as solvent and selector in chiral extraction. J. Chrom. A, 1217, 28, 9, (July 2010) 4669-4674, ISSN 0021-9673

Tomé, L. I. N., Catambas, V. R., Teles, A. R. R., Freire, M. G., Marrucho, I. M., Coutinho, J. A. P. (2010). Tryptophan extraction using hydrophobic ionic liquids. Sep. Purif. Technol., 72, 2, (April 2010) 167-173, ISSN 1383-5866 
Urban, P. L., Goodall, D. M. \& Bruce N. C. (2006). Enzymatic microreactors in chemical analysis and kinetic studies. Biotech. Adv., 24, 1, (January-February 2006), 42-57, ISSN 0734-9750

van Rantwijk, F.; Sheldon, R. A. (2007). Biocatalysis in ionic liquids. Chem. Rev., 107, 6, (June 2007) 2757-2785, ISSN 0010-8545

Wasserscheid, P., Eichmann, M. (2001). Selective dimerisation of 1-butene in biphasic mode using buffered chloroaluminate ionic liquid solvents - Design and application of a continuous loop reactor. Catal. Today, 66, 2-4, (March 2001) 309-316, ISSN 0920-5861

Waterkamp, D. A., Heiland, A., Schlüter, A., Sauvageau, J. C., Beyersdorffb, T., Thöming, J. (2007). Synthesis of ionic liquids in micro-reactors - a process intensification study. Green Chem., 9, (June 2007) 1084 - 1090, ISSN 1463-9270

Waterkmap, D., Engelbert, M., Thöming, J. (2009). On the effect of enhanced mass transfer on side reactions in capillary microreactors during high-temperature synthesis of an ionic liquid. Chem. Eng. Technol. 32, 11, (November 2009) 1717-1723, ISSN 15214125

Wei, G.-T., Yang, Z., Chen, C.-J. (2003). Room temperature ionic liquid as a novel medium for liquid/liquid extraction of metal ions. Anal. Chim. Acta, 488, 2, (July 2003) 183192, ISSN 0003-2670

Welton, T. (1999). Room-temperature ionic liquids. Solvents for synthesis and catalysis. Chem. Rev., 99, (July 1999) 2071-2083, ISSN 0009-2665

Wießmeier, G., Hönicke, D. (1996). Heterogeneously catalyzed gas-phase hydrogenation of cis,trans,trans-1,5,9-cyclododecatriene on palladium catalysts having regular pore systems. Ind. Eng. Chem. Res., 35, 12, (December 1996) 4412-4416, ISSN 0888-5885

Wilms, D., Klos, J., Kilbinger, A.F.M., Löwe, H., Frey, H. (2009). Ionic liquids on the demand in continuous flow. Org. Proc. Res. Dev., 13, 12, (December 1996) 961-964, 0888-5885

Yang, Z., Pan, W. (2005). Ionic liquids: green solvents for nonaqueous biocatalysis, Enzyme and Microb. Technol., 37, 1, (June 2005) 19-28, ISSN 0141-0229

Yoon, S. Y., Lee, J. G., Tajima H., Yamasaki, A., Kiyono, F., Nakazato, T., Tao, H. (2010). Extraction of lanthanide ions from aqueous solution by bis(2-ethylhexyl)phosphoric acid with room-temperature ionic liquids. J. Ind. Eng. Chem., 16, 3, (May 2010) 350354, ISSN 1226-086X

Zhao, D., Wu, M., Kou, Y., Min, E. (2002). Ionic liquids: applications in catalysis. Catal. Today, 74, 1-2, 157-189, ISSN 0920-5861

Zhou, Q., Zhang, X., Xiao, J. (2009). Ultrasound-assisted ionic liquid dispersive liquid-phase micro-extraction: A novel approach for the sensitive determination of aromatic amines in water samples. J. Chrom. A, 1216, 20, (May 2009) 4361-4365, ISSN 15700232

Žnidaršič-Plazl, P., Plazl, I. (2007). Steroid extraction in a microchannel system mathematical modelling and experiments. Lab Chip, 7, 7, (July 2007) 883-889, ISSN 1473-0189

Žnidaršič-Plazl, P., Plazl, I. (2009). Modelling and experimental studies on lipase-catalyzed isoamyl acetate synthesis in a microreactor. Process Biochem., 44, 10, (October 2009) 1115-1121, ISSN 1359-5113

Zimmermann, J., Ondruschka, B., Stark, A. (2010). Efficient synthesis of 1,3dialkylimidazolium-based ionic liquids: The modified continuous Radziszewski 
reaction in a microreactor setup. Org. Process Res. Dev., 14, 5, (August 2010) 11021109, ISSN 1083-6160

Zulfiqar, F., Kitazume, T. (2000). One-pot aza-Diels-Alder reactions in ionic liquids. Green Chem., 2, 137-139, (June 2000) 1463-9262, ISSN 1463-9262 


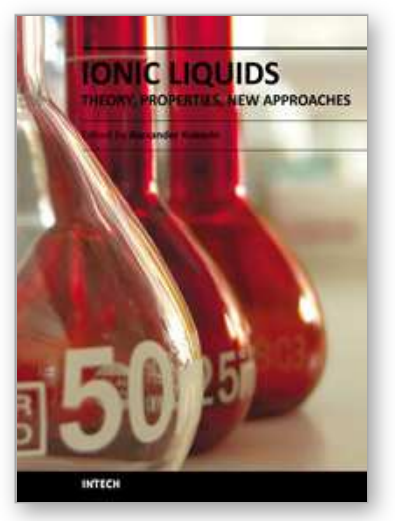

\section{Ionic Liquids: Theory, Properties, New Approaches}

Edited by Prof. Alexander Kokorin

ISBN 978-953-307-349-1

Hard cover, 738 pages

Publisher InTech

Published online 28, February, 2011

Published in print edition February, 2011

Ionic Liquids (ILs) are one of the most interesting and rapidly developing areas of modern physical chemistry, technologies and engineering. This book, consisting of 29 chapters gathered in 4 sections, reviews in detail and compiles information about some important physical-chemical properties of ILs and new practical approaches. This is the first book of a series of forthcoming publications on this field by this publisher. The first volume covers some aspects of synthesis, isolation, production, modification, the analysis methods and modeling to reveal the structures and properties of some room temperature ILs, as well as their new possible applications. The book will be of help to chemists, physicists, biologists, technologists and other experts in a variety of disciplines, both academic and industrial, as well as to students and PhD students. It may help to promote the progress in ILs development also.

\section{How to reference}

In order to correctly reference this scholarly work, feel free to copy and paste the following:

Marina Cvjetko and Polona Žnidaršič-Plazl (2011). Ionic Liquids within Microfluidic Devices, lonic Liquids: Theory, Properties, New Approaches, Prof. Alexander Kokorin (Ed.), ISBN: 978-953-307-349-1, InTech, Available from: http://www.intechopen.com/books/ionic-liquids-theory-properties-new-approaches/ionic-liquidswithin-microfluidic-devices

\section{INTECH}

open science | open minds

\author{
InTech Europe \\ University Campus STeP Ri \\ Slavka Krautzeka 83/A \\ 51000 Rijeka, Croatia \\ Phone: +385 (51) 770447 \\ Fax: +385 (51) 686166 \\ www.intechopen.com
}

\author{
InTech China \\ Unit 405, Office Block, Hotel Equatorial Shanghai \\ No.65, Yan An Road (West), Shanghai, 200040, China \\ 中国上海市延安西路65号上海国际贵都大饭店办公楼 405 单元 \\ Phone: +86-21-62489820 \\ Fax: $+86-21-62489821$
}


(C) 2011 The Author(s). Licensee IntechOpen. This chapter is distributed under the terms of the Creative Commons Attribution-NonCommercialShareAlike-3.0 License, which permits use, distribution and reproduction for non-commercial purposes, provided the original is properly cited and derivative works building on this content are distributed under the same license. 